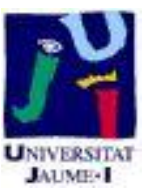

Título artículo / Títol article: Multilayer and Particle Size-Graded YSZ Coatings Obtained by Plasma Spraying of Micro- and Nanostructured Feedstocks

Autores / Autors

Carpio Cobo, Pablo; Bannier, Emilie; Salvador, M.

D.; Benavente, Rut; Sánchez Vilches, Enrique Javier

Revista:

Journal of Thermal Spray Technology

Versión / Versió:

Posr-print

Cita bibliográfica / Cita bibliogràfica (ISO 690):
CARPIO, P., et al. Multilayer and Particle SizeGraded YSZ Coatings Obtained by Plasma Spraying of Micro-and Nanostructured Feedstocks. Journal of Thermal Spray Technology, 2014, vol. 23, no 8, p. 1362-1372.

url Repositori UJI: http://hdl.handle.net/10234/128927 


\title{
Multilayer and particle size graded YSZ coatings obtained by plasma spraying of micro- and nanostructured feedstocks
}

\author{
P. Carpio ${ }^{1, *}$, E. Bannier ${ }^{1}$, M. D. Salvador ${ }^{2}$, R. Benavente ${ }^{2}$, E. Sánchez ${ }^{1}$ \\ ${ }^{1}$ Instituto de Tecnología Cerámica (ITC), Asociación de Investigación de las Industrias \\ Cerámicas (AICE). Universitat Jaume I (UJI), Castellón, Spain. \\ ${ }^{2}$ Instituto de Tecnología de Materiales (ITM), Universitat Politécnica de Valencia \\ (UPV), Valencia, Spain.
}

Pablo Carpio*: corresponding author

Mailing address: Instituto de Tecnología Cerámica. Campus Universitario Riu Sec. Av. Sos Baynat s/n, 12006 Castellón (Spain).

Telephone: $\quad+34964342424$

Fax: $\quad+34964342425$

E-mail: $\quad$ pablo.carpio@itc.uji.es

Emilie Bannier (e-mail: emilie.bannier@itc.uji.es)

María Dolores Salvador (e-mail: dsalva@mcm.upv.es)

Rut Benavente (e-mail: rutbmr@upvnet.upv.es)

Enrique Sánchez (e-mail: enrique.sanchez@itc.uji.es) 


\section{Abstract}

This study was undertaken to attempt to achieve a better balance between zirconia coating properties and high-temperature performance by combining the characteristics of coatings obtained from a micro- and a nanostructured feedstock having the same YSZ composition. First, two single-layer coatings were obtained as reference coatings, using the micro- and the nanostructured feedstock, respectively. Four different composite coatings were then obtained by combining these two feedstocks. Two double-layer (multilayer) YSZ coatings were prepared by depositing the microstructured feedstock on the nanostructured layer and vice versa, while two coatings with different particle size gradients (graded coatings) were prepared by depositing various mixtures of the micro- and the nanostructured feedstock in alternate layers.

The microstructure and hardness of the resulting coatings were determined. In the multilayer coatings, each layer exhibited a clearly different microstructure, whereas in the graded coatings the microstructural characteristics changed gradually. Coating hardness developed analogously, each layer displaying a marked change in hardness in the multilayer coatings in contrast to a gradual change in the graded coatings. The microstructure and hardness of the individual layers were thus quite well preserved in the developed composite coatings.

Keywords: Atmospheric Plasma Spraying; Thermal Barrier Coating; YSZ; Gradient Coating; Multilayer Coating 


\section{Introduction}

Plasma sprayed thermal barrier coatings (TBCs) are traditionally applied to gas turbine engines blades and vanes to reduce their operating temperatures and increase component durability. The state-of-the-art TBC system consists of a duplex coating made up of a thermally insulating yttria-stabilised zirconia YSZ top coat applied over an oxidation-resistant MCrAlY ( $\mathrm{M}=\mathrm{Ni}$ and/or Co) bond coat $(\operatorname{Ref} 1,2)$.

Nanostructured coatings have been extensively studied in the last decade, and thermal spraying is one of the techniques commonly used to obtain such layers. In fact, coatings exhibiting different architectures and interesting properties can be obtained by using nanostructured feedstock in plasma spraying (Ref 3). However, nanoparticles cannot be directly sprayed because of their low mass and poor flowability. To overcome these problems, the individual nanoparticles need to be reconstituted into spherical micrometre-sized granules. Spray drying a nanoparticle suspension is one of the most widely used agglomeration methods. Often it is followed by thermal treatment of the resulting nanostructured granules to enhance their sinterability (reducing porosity) and cohesive strength. Plasma spray deposition of such agglomerates leads to a two-scale microstructure that basically consists of partially melted agglomerates (nanozones) surrounded by fully melted areas, which act as a binder matrix (Ref 4,5$)$.

In view of this microstructure, a well-reported research approach has been developed, aimed at preserving as much as possible the nanostructured character of the agglomerate feedstock without adversely affecting coating adhesion and cohesion. Spray parameters were therefore optimised to achieve conditions (particle temperature and velocity) that resulted in only partial melting of the agglomerates (to avoid complete loss of the nanostructure), albeit with a sufficient degree of melting to ensure effective deposition on the substrate. In addition, depending on the thermal processing, spraying conditions, 
and feedstock characteristics (agglomerate diameter and porosity), the nanozones in the resulting coating might continue to be porous like the original agglomerate feedstock or be much denser $(\operatorname{Ref} 4)$.

In the case of YSZ coatings for thermal barriers, nanostructured coatings can provide better performance than that of their conventional counterparts (Ref 6). Controlling the amount of melted and porous partially melted particles embedded in a coating microstructure, thus enables considerable modification of coating mechanical and thermal response (Ref 7). In particular, the literature reports that the non-melted nanostructured zones present in YSZ coatings obtained by atmospheric plasma spraying (APS) decrease the thermal conductivity and increase the thermal shock resistance of thermal barriers (Ref 4) compared to the same properties of coatings obtained from conventional, micrometre-sized powders. Nanostructured coatings have also been shown to exhibit improved compliance characteristics (Ref 7,8).

However, fundamental questions still remain to be answered on the applicability of nanostructured YSZ coatings as TBCs. These questions are related to sintering effects, which could significantly increase the thermal diffusivity/conductivity and elastic modulus values of these types of coatings in high-temperature environments. Such effects are related to the fine microstructure of nanozones that contain nano/submicronsized particles and pores (Ref 4, 5).

The above suggested the interest of exploring the possibility of combining the properties/performance of conventional (microstructured) and nanostructured layers in designing new types of YSZ-based TBCs, using their respective benefits. It was considered that such coatings might be obtained by using two approaches: a doublelayer (multilayer) assembly of micro- and nanostructured layers and a graded assembly, 
in which the micro- and/or nanostructured feedstock-containing layers could be gradually changed.

A literature review showed extensive use of multilayer and graded layer approaches for TBCs, indicating that such combinations might be key factors in the high performance and durability of TBC systems. Indeed, studies have explored graded layers, combining a bond coat composition and top coat composition (Ref 9); multilayer coatings, combining ceramic oxides other than zirconia (Ref 10-12); and even a graded YSZ top coat with porosity gradient (Ref 13) to obtain the benefits of composite materials. However, the combination of micro- and nanostructured layers as addressed the present study has not been reported.

This paper describes an attempt to develop YSZ-based coatings through composite design. Using a micro- and a nanostructured commercial feedstock, two approaches were explored. First, two double-layer coatings were obtained, depositing the micro- on the nanostructured feedstock in the one and performing the deposition in the opposite order in the other. Secondly, two graded coatings were obtained, progressively depositing micro- to nanostructured feedstock and nano- to microstructured feedstock, respectively. All coatings were microstructurally and mechanically characterised and compared with two single-layer coatings, used as references, obtained using the microand the nanostructured feedstock, respectively.

\section{Experimental}

\subsection{Materials}

Two commercial feedstock powders for obtaining a conventional and a nanostructured $\mathrm{Y}_{2} \mathrm{O}_{3}$-stabilised $\mathrm{ZrO}_{2}$ (YSZ) layers were used in this study. The feedstock characteristics provided by the suppliers are given in table 1. Granule apparent specific 
mass ( $\left.\rho_{\text {granule }}\right)$ was calculated from powder tapped specific mass, assuming a theoretical packing factor of 0.6, which is characteristic of monosized, spherical particles (Ref 14). The crystalline phases in these feedstocks were identified by X-ray diffraction (D8 Advance, Bruker AXS, Germany). In addition, a field-emission scanning electron microscope (QUANTA 200FEG, FEI Company, USA) was used to analyse feedstock microstructure.

\subsection{Coating deposition}

The YSZ layers of the two feedstocks (a conventional and a nanostructured powder) were deposited onto stainless steel (AISI 304) substrates by an atmospheric plasma spray (APS) system. The system consisted of a gun (F4-MB, Sulzer Metco, Germany) operated by an industrial robot (IRB 1400, ABB, Switzerland). Before spraying, the substrate was grit-blasted with corundum at a pressure of 4.2 bar and cleaned with ethanol to remove any remaining dust or grease from the surface. A bond coat (AMDRY 997, Sulzer-Metco, Germany) was used to enhance the adhesion between the substrate and the ceramic layers. Bond coat composition was Ni-23Co-20Cr-9Al-4.2Ta0.6Y (mass fraction, \%). Deposition was performed using argon and hydrogen as plasma-forming gases. The main spraying parameters are listed in table 2 .

Two independent feed systems (one for each powder), with their respective circuits, were used to obtain the multilayer and the graded coatings. The two powders were thus injected into the plasma plume via two different nozzles arranged radially around the torch. To assure adequate powder flow through each feed system, 3 slpm (standard litre per minute) of argon flow was used. The multilayer coatings were obtained by first applying five passes of one feedstock (starting one feed system after stopping the other) and then applying five passes of the other feedstock (stopping the first feed system and 
starting the other). Two types of multilayer coating (M1 and M2) were prepared as detailed in table 3 . The M1 coating was obtained by first depositing the conventional and then the nanostructured feedstock. The M2 coating was obtained by depositing the feedstock in the opposite order. The graded coatings were prepared by varying the powder mass flow rate of each feedstock in the feed system while keeping a constant mass flow rate of $45 \mathrm{~g} / \mathrm{min}$ for the total powder. Two series of graded coatings (G1 and G2) were obtained: in the G1 coating, the bottom layer consisted of a $100 \%$ conventional powder deposition and the top layer a 100\% nanostructured powder deposition, whereas in G2 the opposite order was used. Five layers were prepared for each series, using the following composition for each feedstock: 100\%, 75\%, 50\%, $25 \%$, and $0 \%$. The plasma spraying parameters of the bond coat and YSZ layers are given in table 2 . Figure 1 schematically illustrates the two graded coatings. The total thickness of each composite coating (both M and G) was about $150 \mu \mathrm{m}$.

\subsection{Coating characterisation}

The compositions of the crystalline phases in the coatings were identified by X-ray diffraction (XRD). XRD patterns were obtained of each layer in the M1 and M2 coatings. To obtain the XRD pattern of the bottom layer (the layer on the bond coat), an approximately $100 \mu \mathrm{m}$ thick layer of the coating was removed to assure the top layer had been eliminated. A field-emission scanning electron microscope (JEOL 7001F, Jeol Ltd., Japan) was used to analyse coating microstructure on the polished cross-section areas. Voids and partially melted areas of the single-layer coatings used as references (obtained from the conventional and the nanostructured feedstock, respectively) were evaluated by image analysis from 10 micrographs at 500x magnification. The average values were then calculated. Vickers microhardness was measured with a LECO M400 
microhardness tester (Leco Co., USA), 10 indentations being performed on each sample (50 g load for $10 \mathrm{~s})$. These microhardness measurements were made on polished specimens across the entire cross-section. In the case of the M1 and M2 coatings, indentations were performed on each micro- and nanostructured layer, the layers being clearly identifiable in the optical microscope coupled with the microhardness tester. A different approach was used for the G1 and G2 coatings, however, as the layers could not be readily identified. In this case, the total thickness of every graded coating (G1 or G2) was divided into five identical portions, which were then indented as set out above.

\section{Results and discussion}

\subsection{Feedstock characterisation}

FEG-SEM micrographs of the conventional and the nanostructured powder used are shown in figure 2. It can be observed that both powders consisted of spherical granulates of agglomerated particles, whose average size was about $400-800 \mathrm{~nm}$ in the conventional powder and $200 \mathrm{~nm}$ in the nanostructured powder. This morphology suggests that the powders were obtained by a spray-drying process. In addition, as observed in the magnified micrograph, the partially sintered microstructure of the agglomerates in the conventional powder indicates that a thermal treatment was used to suitably reconstitute this powder for thermal spraying. This type of partially sintered granulate feedstock is generally known as HOSP (hollow spherical powder). Information on these two powders is provided elsewhere (Ref 7).

Figure 2 also shows that the nanostructured agglomerates were much more porous than the conventional agglomerates. Indeed, the measured agglomerate specific mass of the

conventional and the nanostructured powder was $4500 \mathrm{~kg} / \mathrm{m}^{3}$ and $2400 \mathrm{~kg} / \mathrm{m}^{3}$, respectively. This is of great significance for the subsequent plasma spraying process, as 
agglomerate porosity can govern the degree of nanoparticle melting during the deposition process. Apart from the powder agglomerate sintering state, the differences in agglomerate structure largely depend on the characteristics of the spray-drying suspensions used to produce the powders. This is because obtaining suspensions with higher solids content becomes much more difficult as the solids particle size in the suspension decreases to the nanometre range (Ref 15,16$)$.

\subsection{Microstructural characteristics of the double-layer and the graded coatings}

Coating microstructure was characterised using FEG-SEM. For the sake of comparison, first, microstructural observation was performed of the single-layer coatings used as references, obtained from the conventional and the nanostructured feedstocks, respectively, under the standard spray conditions set out in table 2 . Figure 3 shows the corresponding micrographs of these two coatings. Their average thickness was about $150 \mu \mathrm{m}$. Both coatings displayed a 'splat-like' structure formed by flatenned drops or splats, which is typical of thermal spray deposition. Intersplat cracks associated with fast cooling after deposition were also evident in both specimens, in particular in the case of the conventional coating. The coating obtained from the nanostructured feedstocks displayed the expected bimodal microstructure, characterised by the presence of partially melted agglomerates that retained the initial nanostructure of the feedstock powders. Such zones are usually known as partially melted areas, and they result from a low degree of melting during spraying. In this study, these areas are referred to as partially melted areas (marked PM in the micrograph). The PM areas were surrounded by a large dense smooth structure of fully (or almost fully) melted splats (marked $\mathrm{M}$ in the micrograph). Figure 4 shows higher magnification FEG-SEM micrographs of these partially melted areas in the nanostructured YSZ coatings. The initial nanostructure of 
the feedstock was largely retained in the partially melted areas, though some sintering and consequent grain growth were observed. Zones resembling the nanostructured feedstock (PM) therefore exhibited a similar structure to that of the feedstock agglomerates (figure 2), displaying an agglomeration of particles loosely bound to each other (Ref 4, 5). The particle size in these areas (about $200 \mathrm{~nm}$ ) confirmed that they were partially melted feedstock agglomerates. However, partially melted zones were not observed in the conventional coating, despite the fact that the conventional powder agglomerates were made up of larger particles. This was caused by the much higher degree of sintering of the HOSP agglomerates, which gave rise to a dense, uniform microstructure that differed significantly from that of the coating obtained from the highly porous nanostructured agglomerates. This type of two-zone (bimodal) microstructure has been widely reported in the literature with YSZ and other oxide feedstocks (Ref 4, 5). The amount and porosity of these nanostructured areas largely depend on the thermal processing, spraying conditions, and feedstock characteristics.

The total porosity of the coatings, as well as the amount of partially-melted areas, was estimated by image analysis at 500 magnifications from SEM pictures following a procedure set out elsewhere (Ref 16). Figure 5 shows the porosity and partially-melted areas found in the two reference single-layer coatings. The porosity data agree with the typical values observed in these types of coatings. As may be observed, the quantified porosity, as well as the amount of partially-melted areas for these two individual coatings, agreed well with the inference drawn from the corresponding micrographs in figure 3.

The splat shape modes observed in the coating microstructures obtained from both feedstocks were determined from the spread factor $(\xi)$, defined as the quotient of droplet diameter (considered the same as the agglomerate diameter) divided by splat diameter 
(deposited drops which form the coating). These factors were calculated for each feedstock using the Madejski model (Ref 17), the spread factors being 5.0 and 4.8 for the conventional and for the nanostructured feedstock, respectively. These values indicate that the coatings were made up of flattened splats, as the corresponding micrographs in figure 3 show.

The FEG-SEM micrographs of the M1 and M2 coatings are shown in figure 6. A general micrograph is shown for each coating, together with magnified images of two successive portions of the coating cross-section, from the bond coat interface to the top layer surface. The general microstructure of the M1 and M2 coatings can readily identified in their constituent layers by comparing the micrographs of the single-layer conventional and nanostructured coatings in figure 3. The M1 and M2 coatings displayed two clearly distinct areas, defined by the amount of partially melted areas (PM areas in figure 3), which were in turn directly related to the layer deposited from the nanostructured feedstock. As expected, the PM areas were concentrated in the top layer of the M1 coating, where nanostructured feedstock had been sprayed. In contrast, the M2 coating displayed the opposite microstructure, as the PM areas were located in the layer on the bond coat, where the nanostructured feedstock had been deposited. The change in microstructural characteristics was not gradual: the PM areas only appeared where the nanostructured feedstock had been applied. In addition, large PM areas adversely affected coating microstructural homogeneity, as observed in the top layer of the M1 coating and at the interface of the conventional top layer and the nanostructured bottom layer in the M2 coating. Consequently, from a microstructural point of view, the combination used in the M2 coating appeared inappropriate in terms of coating integrity. 
Figure 7 shows a similar set of micrographs for graded coatings G1 and G2. In this case, to better observe the microstructural changes, five micrographs are shown for each coating. Again, the amount of PM areas can be used as trace feature to analyse the microstructure of these coatings. In the G1 coating, the amount and size of the PM areas gradually increased from the bond coat interface to the top layer, paralleling the increase in nanostructured feedstock content in the deposited mixture. There was thus no distinct interface between any two adjacent layers, indicating an appropriately graded structure. In the G2 coating, the amount and size of the PM areas decreased from the bond coat interface to the top layer surface as the nanostructured feedstock content decreased in the same direction. Unlike the M1 and M2 coatings, the G1 and G2 coatings displayed a gradual change in microstructural characteristics, as PM areas could be observed to a greater or lesser extent throughout the coating cross-sections. Consequently, the G1 and G2 coatings exhibited greater microstructural homogeneity than the M1 and M2 coatings.

Coating phase composition was determined by X-ray diffraction. Overall, the XRD patterns of the layers obtained from both the conventional and the nanostructured feedstock identical in the M1 and M2 coatings, regardless of layer position. Figure 8 shows the XRD patterns corresponding to the top layer of the M1 coating (deposited from nanostructured feedstock) and the top layer of the M2 coating (deposited from conventional feedstock). For comparative purposes, figure 8 also shows the XRD patterns of both feedstocks.

The figure shows that both layers retained the crystalline composition (mainly tetragonal YSZ) of the feedstock powders, as reported elsewhere (Ref 18, 19). Furthermore, the as-sprayed conventional layer (top layer in the M2 coating) hardly contained any monoclinic zirconia despite the presence of this phase in the 
corresponding feedstock. These results evidence the good melting of the YSZ powders. The disappearance of the monoclinic phase is thought to result from the subsequent high quenching rate following coating deposition. Finally, the XRD patterns of the top layers of the G1 coating (obtained from 100\% nanostructured feedstock) and the G2 coating (obtained from $100 \%$ conventional feedstock) closely resembled the XRD diffractograms of the corresponding layers in the M1 and M2 coatings.

\subsection{Hardness measurements}

Figures 9 (a) to (d) show the hardness values of the four types of coating assembly prepared in this study. The graphs for the M1 and M2 coatings ((a) and (b), respectively) are shown in histogram form. On the other hand, coating hardness was plotted versus thickness for graded coatings G1 and G2 ((c) and (d), respectively). The average hardness of the layers in the M1 and M2 coatings, obtained from the conventional and the nanostructured feedstock, was calculated for comparative purposes. Average hardness was $4.5 \pm 0.7 \mathrm{GPa}$ and $2.2 \pm 0.5 \mathrm{GPa}$ for the conventional and for the nanostructured layer, respectively. According to the literature, the lower hardness of coatings obtained from nanostructured feedstock is related to the higher porosity of these coatings, as well as to the presence of the mechanically weak nanozones that characterise these coatings (Ref 20, 21). In addition, the high standard deviation of the hardness data in this last coating stemmed from the higher heterogeneity associated with microstructures containing these nanozones. The influence of nanozones on coating hardness was also reported by Lima et al. (Ref 22). These authors predicted that hardness would be lower in regions where there was a preferable concentration of partially melted areas. The porous nanograin agglomeration containing these PM regions was also argued as the reason for the lower hardness in 
these partially melted areas. Despite this difference in hardness, the literature also indicates that the bimodal structure associated with nanostructured coatings can enhance other mechanical properties, such as toughness and wear resistance (Ref 4).

With regard to coatings M1 and M2, figures 9 (a) and (b) show that, as expected from the porosity and amount of partially melted areas present in the two reference singlelayer coatings (see figure 5), hardness changed markedly across the coating thickness. Hardness thus decreased dramatically on passing from the layer obtained from the conventional powder to that obtained from the nanostructured feedstock. This was because the layers making up the double-layered composites largely preserved their microstructure and, hence, hardness values of the corresponding single-layer coatings. In addition, the M1 coating top layer (obtained from the nanostructured feedstock) exhibited exceptionally low hardness, owing to its poor microstructural homogeneity, as set out in the previous section (figure 6). The preservation of the microstructural characteristics and hardness of the respective layers in the M1 and M2 coatings there was little interaction between both types of layer during deposition.

In contrast, in the graded coatings, assuming that the variation in porosity and amount of partially melted areas followed the gradual variation of the composite layers, a corresponding gradual variation in hardness might be expected. The variation of G1 and G2 coating hardness with thickness is plotted in Figures 9 (c) and (d), respectively. Note that, in these figures, $0 \mu \mathrm{m}$ refers to the bond coat interface and $150 \mu \mathrm{m}$ to the top coat surface. As may be observed, these coatings exhibited a gradual change in hardness, with no steep interface. The increase in hardness paralleled the increasing conventional feedstock content in the deposited mixtures, i.e. from top layer to bottom layer in the G1 coating and in the opposite direction in the G2 coating. These results match the variation observed in the microstructural characteristics illustrated in figure 7 . To 
confirm the effect of feedstock composition on coating hardness, hardness data of coatings G1 and G2 were plotted against the nanostructured feedstock content of the deposited mixtures in figures 10 (a) and (b), respectively. To determine whether the variation in hardness obeyed a mixture law, considering the average measured hardness values of the reference single-layer coatings obtained from the conventional and the nanostructured feedstock as set out above, the following equation was used:

$H V(n)=H V_{n} \cdot n+H V_{c} \cdot(1-n)$

where $\mathrm{HV}(\mathrm{n})$ is the hardness as a function of the nanostructured feedstock mass fraction, $\mathrm{HV}_{\mathrm{n}}$ and $\mathrm{HV}_{\mathrm{c}}$ represent the hardness of the coatings obtained from the nanostructured and conventional feedstocks, respectively (as set out above), and $\mathrm{n}$ is the nanostructured feedstock mass fraction. Figure 10 shows the plot of the variation in hardness of the graded coatings, according to this mixture law. The plot displays a straight trend line, indicating that the variation in hardness practically followed a simple mixture law (linear variation), again confirming the little interaction between the feedstocks of the deposited mixtures.

To better explain the physical reasons for this behaviour, in addition to the above variation in hardness of the G1 and G2 coatings versus the nanostructured feedstock content in the deposited mixtures, the estimated variation in porosity and amount of partially melted areas in these coatings with the nanostructured feedstock content have also been plotted in figure 10. This estimate was made on the basis of the measured values of porosity and amount of partially melted areas in the single-layer coatings shown in figure 5. Note that this estimate relied on the little interaction observed between the layers during the deposition of the G1 and G2 coatings, as set out above. As may be observed, the plots in figure 10 confirm that the gradual variation in hardness of the G1 and G2 coatings stemmed mainly from the gradual variation of the 
two influencing variables, namely porosity and amount of partially melted areas, as long as the microstructure of the successive feedstock layer made up of the mixture of the studied conventional and nanostructured feedstocks was largely preserved. However, the relative contribution of these two variables (porosity and amount of partially melted areas) to the hardness of the layers making up the composite coatings needs to be determined by further measurements.

Similar findings single-layer coatings obtained from nanostructured feedstocks were previously reported (Ref 22). In that research, coating microhardness could be predicted on the basis of the amount of melted and partially melted areas in the coating layer. However, for that calculation, the amount of these two types of areas needed to be previously determined, which made predicting microhardness more difficult.

Finally, although not determined in this study, the elastic modulus may be expected to follow the same trend as that exhibited by hardness in the G1 and G2 coatings, on the basis of previously reported data (Ref 20, 23, 24). Further research is now in progress to complete the mechanical and thermal characterisation of these graded coatings.

The results obtained in this study represent an interesting starting point for designing new nanostructured feedstock-based coatings in which mechanical and presumably thermal properties can be graded from the bond coat interface to the top coat surface. Coatings could thus be tailored with variable nanozone contents, increasing from the bond coat to the surface, to provide better thermomechanical performance at the surface while keeping the adherence and residual stresses at the bond coat interface as a result of the prevalent conventional feedstock coating in the bottom layer (Ref 13). No less importantly, graded nanozone development could widen the relatively narrow processing window of plasma spray conditions that usually characterises the production of these bimodal plasma spray coatings as recognised elsewhere (Ref 3-5). 


\section{Conclusions}

Four different composite coatings were obtained by combining a conventional (microstructured) and a nanostructured feedstock having the same YSZ composition. Two double-layer (multilayer) YSZ coatings were thus prepared by depositing the microstructured feedstock on the nanostructured layer and vice versa. On the other hand, two coatings were prepared with different particle size gradients (graded coatings) by depositing various mixtures of the micro- and the nanostructured feedstock in alternate layers. All coatings were microstructurally and mechanically characterised and compared with two single-layer coatings used as references, obtained using the microand the nanostructured feedstock, respectively.

The multilayer coating microstructure exhibited two clearly distinct areas, defined by the amount of partially melted areas (PM areas), which were in turn directly related to the layer deposited using the nanostructured feedstock. The PM areas were thus exclusively concentrated in the layer obtained from the nanostructured feedstock. This caused a marked change in hardness across the coating thickness, as the layers in these composites largely preserved the hardness of the corresponding reference single-layer coating.

In the graded coatings, the amount and size of the PM areas gradually varied from the bond coat interface to the top layer, paralleling the variation in nanostructured feedstock content in the deposited mixture. There was no distinct interface between any two adjacent layers, and a gradual change in hardness was observed. The variation in hardness fitted a simple mixture law (linear variation), confirming an appropriately graded structure as well as little interaction between the feedstocks in the deposited mixtures. 
The results obtained in this study can contribute to the groundwork for the design of new nanostructured feedstock-based coatings in which the mechanical and thermal properties can be gradually changed across the coating thickness by using feedstock having the same composition but different particle sizes.

\section{Acknowledgements}

This work has been supported by the Spanish Ministry of Science and Innovation (project MAT2012-38364-C03) and the Research Promotion Plan of Universitat Jaume I, action 3.1 (ref. PREDOC/2009/10), and it has been co-funded by the ERDF (European Regional Development Fund). The authors also thank the SCIC of Universitat Jaume I for the FEG-SEM observations. 


\section{References}

1. D. R. Clarke, S. R. Phillpot, Thermal Barrier Coatings Materials, Mater. Today, 2005,8, p $22-29$

2. N. P. Patdure, M. Gell, E. H. Jordan, Thermal Barrier Coatings for Gas-Turbine Engine Applications, Science, 2002, 296, p 280-284

3. L. Pawlowski, Finely Grained Nanometric and Submicrometric Coatings by Thermal Spraying: A Review, Surf. Coat. Technol. 2008, 205(43), p 18-28

4. R. S. Lima, B. R. Marple, Thermal Spray Coatings Engineered from Nanostructured Ceramic Agglomerated Powders for Structural, Thermal Barrier and Biomedical Applications: A Review, J. Ther. Spray Technol., 2007, 16(1), p $40-63$

5. P. Fauchais, G. Montavon, R. S. Lima, B. R. Marple, Engineering a New Class of Thermal Spray Nano-Based Microstructures from Agglomerated Nanostructured Particles, Suspensions and Solutions: An Invited Review, J. Phys. D: Appl. Phys., 2011, 44 (9) 93001, p 1-131

6. M. Gell, E. H. Jordan, Y. H. Sohn, D. Goberman, L. Shaw, T. D. Xiao, Development and Implementation of Plasma Sprayed Nanostructured Ceramic Coatings, Surf. Coat. Technol. 2001, 146-147, p 48-54

7. R. S. Lima, B. R. Marple, Nanostructured YSZ Thermal Barrier Coatings Engineered to Counteract Sintering Effects, Mater. Sci. Eng. A, 2008, 485. p 182193

8. H. Chen, X. Zhou, C. Ding, Investigation of the Thermomechanical Properties of a Plasma-Sprayed Nanostructured Zirconia Coating, J. Eur. Ceram. Soc. 2003, 23, p $1449-1455$ 
9. K. A. Khor, Y. W. Gu, Thermal Properties of Plasma-Sprayed Graded Thermal Barrier Coatings, Thin Solid Films, 2000, 372, p 104-113

10. A. M. Limarga, T. S. Widjajab, T. H. Yip, Mechanical Properties and Oxidation Resistance of Plasma-Sprayed Multilayered $\mathrm{Al}_{2} \mathrm{O}_{3} / \mathrm{ZrO}_{2}$ Thermal Barrier Coatings, Surf. Coat. Technol. 2005, 197, p 93- 102

11. X. Chen, Y. Zhao, X. Fan, Y. Liu, B Zou, Y. Wang, H. Ma, X. Cao, Thermal Cycling Failure of New $\operatorname{LaMgAl}_{11} \mathrm{O}_{19} / \mathrm{YSZ}$ Double Ceramic Top Coat Thermal Barrier Coating Systems, Surf. Coat. Technol. 2011, 205, p 3293-3300

12. G. Mauer, M. O. Jarligo, D. E. Mack, R. Vassen, Plasma-Sprayed Thermal Barrier Coatings: New Materials, Processing Issues and Solutions, J. Therm. Spray Technol. 2013, 22(5), p 647-658

13. A. Portinha, V. Teixeira, J. Carneiro, J. Martins, M. F. Costa, R. Vassen, D. Stoever, Characterization of Thermal Barrier Coatings with a Gradient in Porosity, Surf. Coat. Technol., 2005, 195, p 245- 251

14. M. Vicent, E. Sánchez, G. Mallol, R. Moreno, Study of Colloidal Behaviour and Rheology of $\mathrm{Al}_{2} \mathrm{O}_{3}-\mathrm{TiO}_{2}$ Nanosuspensions to Obtain Free-flowing Spray-dried Granules for Atmospheric Plasma Spraying, Ceram. Int. 2013, 39(7), p 8103-8111

15. F. Müller, W. Peukert, R. Polke, R. Stenger, Dispersing Nanoparticles in Liquids, Int. J. Miner. Process., 2000, 74, p S31-S34

16. M. Vicent, E. Bannier, R. Moreno, M. D. Salvador, E. Sánchez, Atmospheric Plasma Spraying Coatings from Alumina-Titania Feedstock Comprising Bimodal Particle Size Distributions, J. Eur. Ceram. Soc., 2013, 33, p 3313-24

17. C. W. Kang, H. W. Ng, Splat Morphology and Spreading Behaviour due to Oblique Impact of Droplets onto Substrates in Plasma Spray Coating Process, Surf. Coat. Technol, 2006, 200, p 5462-5477 
18. Y. Zeng, S. W. Lee, L. Gao, C. X. Ding, Atmospheric Plasma Sprayed Coatings of Nanostructured Zirconia, J. Eur. Ceram. Soc. 2002, 22, p 347-351

19. R. S. Lima, A. Kucuk, C. C. Berndt. Integrity of Nanostructured Partially Stabilized Zirconia After Plasma Spray Processing, Mater. Sci. Eng. A 2001, 13, p 75-82

20. L. Wang, Y. Wang, X. G. Sun, J. Q. He, Z. Y. Pan, C. H. Wang. Microstructure and Indentation Mechanical Properties of Plasma Sprayed Nano-bimodal and Conventional $\mathrm{ZrO}_{2}-8 \mathrm{wt} \% \mathrm{Y}_{2} \mathrm{O}_{3}$ Thermal Barrier Coatings, Vacuum 2012, 86(8), p $1174-1185$

21. L. L. Shaw, D. Goberman, R. Ren, M. Gell, S. Jiang, Y. Wang, T. D. Xiao, P. R. Strutt, The Dependency of Microstructure and Properties of Nanostructured Coatings on Plasma Spray Conditions, Surf. Coat. Technol. 2000, 130(1), p 1-8

22. R. S. Lima, A. Kucuk, C. C. Berndt, Bimodal Distribution of Mechanical Properties on Plasma Sprayed Nanostructured Partially Stabilized Zirconia, J. Mat. Sci. Eng. A, 2002, 327, p 224-232

23. T. Wakui, J. Malzbender, R. W. Steinbrech, Strain Dependent Stiffness of Plasma Sprayed Thermal Barrier Coatings, Surf. Coat. Technol., 2006, 200 (16-17p 49955002

24. J. Malzbender, R. W. Steinbrech, Determination of the Stress-Dependent Stiffness of Plasma-Sprayed Thermal Barrier Coatings Using Depth-Sensitive Indentation, J. Mater. Res. 2003, 18(8), p 1975-1984 


\section{Figure captions}

Figure 1. Schematic illustration of the two composite coating series with particle size gradients: (a) G1 coating and (b) G2 coating (c: conventional feedstock, n: nanostructured feedstock).

Figure 2. FEG-SEM micrographs of (a) METCO 204 conventional powder and (b) NANOX $^{\mathrm{TM}}$ S4007 nanostructured powder.

Figure 3. FEG-SEM micrographs of the single-layer (a) conventional YSZ coating and (b) nanostructured YSZ coating, obtained using standard spraying parameters. The melted and the partially melted areas are referenced M and PM, respectively.

Figure 4. High magnification FEG-SEM micrographs of partially melted (PM) areas present in the nanostructured YSZ coating.

Figure 5. Porosity and partially melted areas of the reference single-layer coatings determined by SEM.

Figure 6. FEG-SEM micrographs corresponding to the M1 (left) and M2 (right) doublelayer coatings.

Figure 7. FEG-SEM micrographs corresponding to the G1 (left) and G2 (right) graded coatings.

Figure 8. X-ray diffraction patterns of the conventional and the nanostructured YSZ feedstock used (top), and top layers of the as-sprayed M1 and M2 coatings (bottom): (a) conventional feedstock or top layer deposited from this feedstock in the M2 coating and (b) nanostructured feedstock or top layer deposited from this feedstock in the M1 coating).

Figure 9. Hardness values of the constituent layers in the M1 and M2 coatings ((a) and (b), respectively) and variation of hardness with coating thickness of the G1 and G2 
coatings ((c) and (d), respectively). Note that $0 \mu \mathrm{m}$ refers to the bond coat interface and $150 \mu \mathrm{m}$ refers to the top coat surface.

Figure 10. Comparison of the variation of the measured hardness with nanostructured feedstock content in the deposited mixtures in coatings G1 and G2 ((a) and (b), respectively) and estimate of the variation in porosity and amount of partially melted areas in these same coatings (the fit of the experimental points displayed a straight trend line). 


\section{Figures}

\begin{tabular}{|c|}
\hline $100 \% \mathrm{n}$ \\
\hline $25 \% \mathrm{c}+75 \% \mathrm{n}$ \\
\hline $50 \% \mathrm{c}+50 \% \mathrm{n}$ \\
\hline $75 \% \mathrm{c}+25 \% \mathrm{n}$ \\
\hline $100 \% \mathrm{c}$ \\
\hline Bond coat \\
\hline Substrate \\
\hline
\end{tabular}

G1

\begin{tabular}{|c|}
\hline $100 \% \mathrm{c}$ \\
\hline $75 \% \mathrm{c}+25 \% \mathrm{n}$ \\
\hline $50 \% \mathrm{c}+50 \% \mathrm{n}$ \\
\hline $25 \% \mathrm{c}+75 \% \mathrm{n}$ \\
\hline $100 \% \mathrm{n}$ \\
\hline Bond coat \\
\hline Substrate \\
\hline
\end{tabular}

G2

\section{Figure 1}
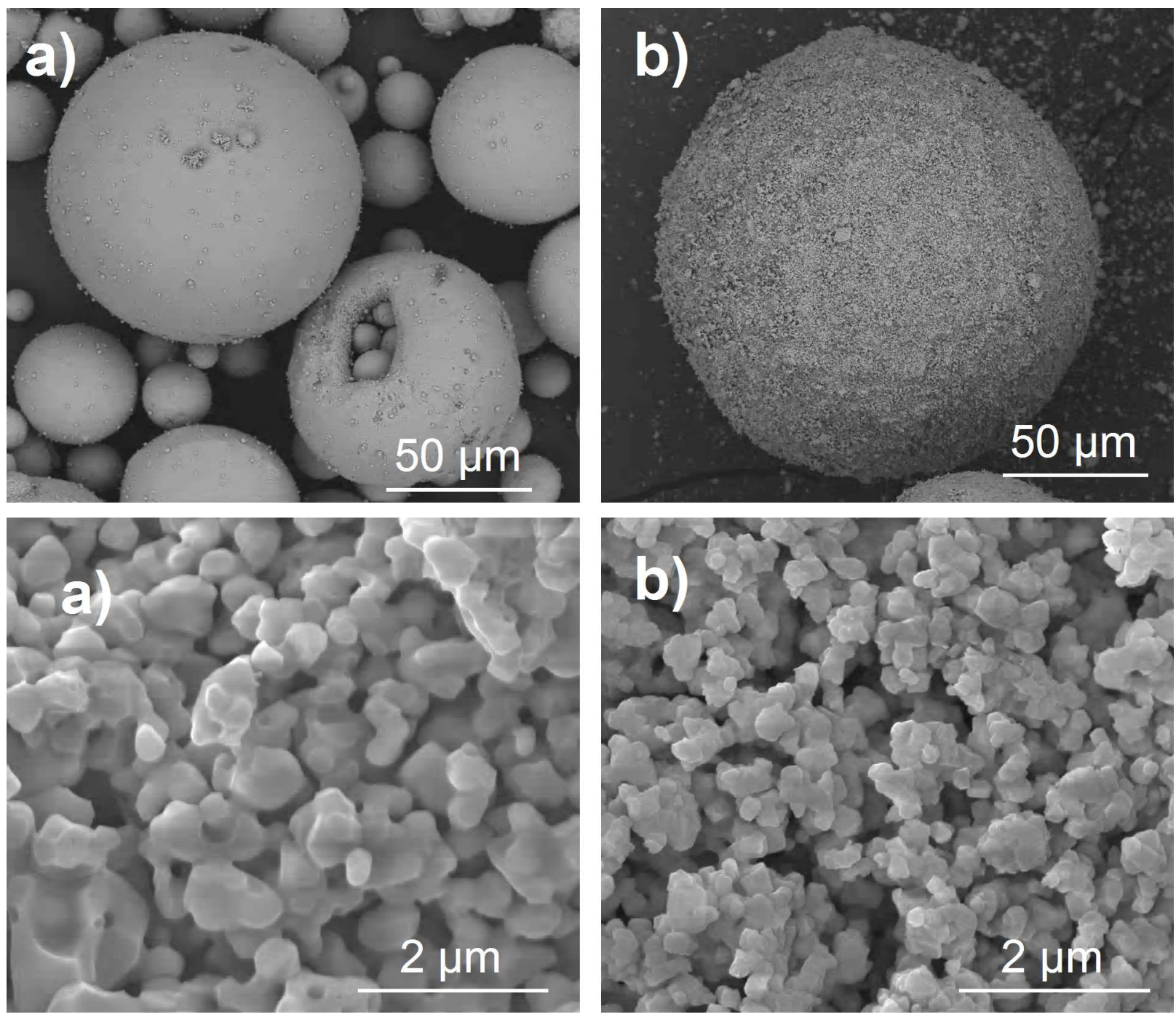

Figure 2 

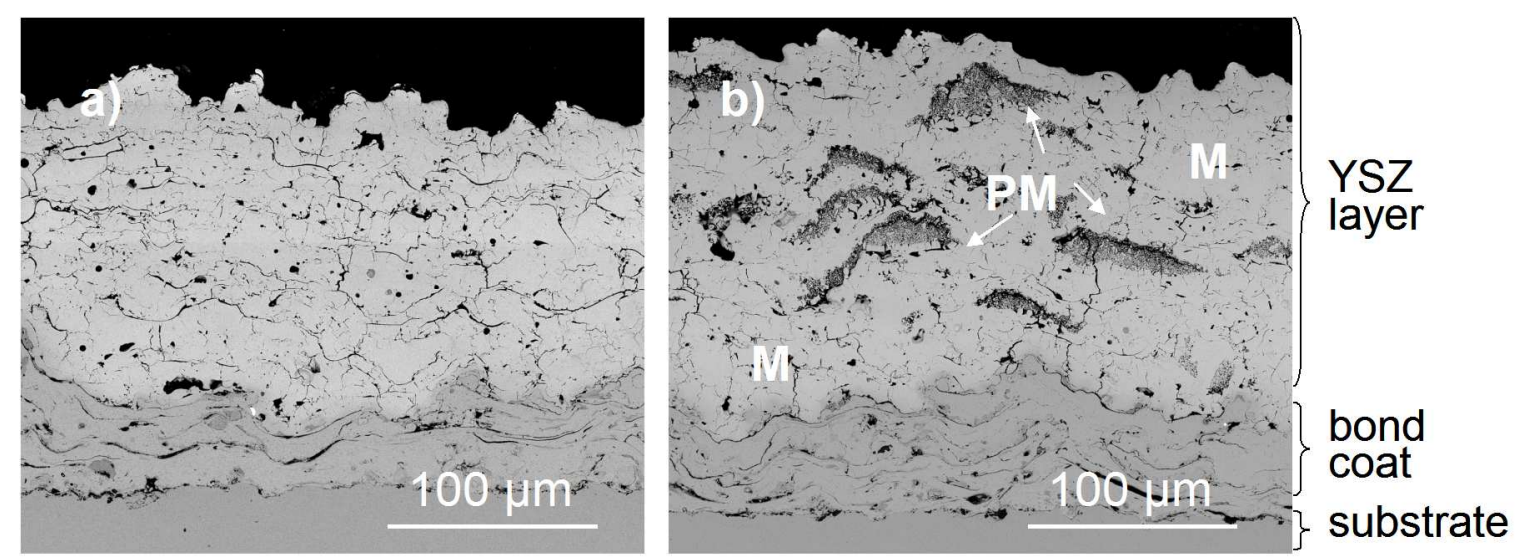

Figure 3

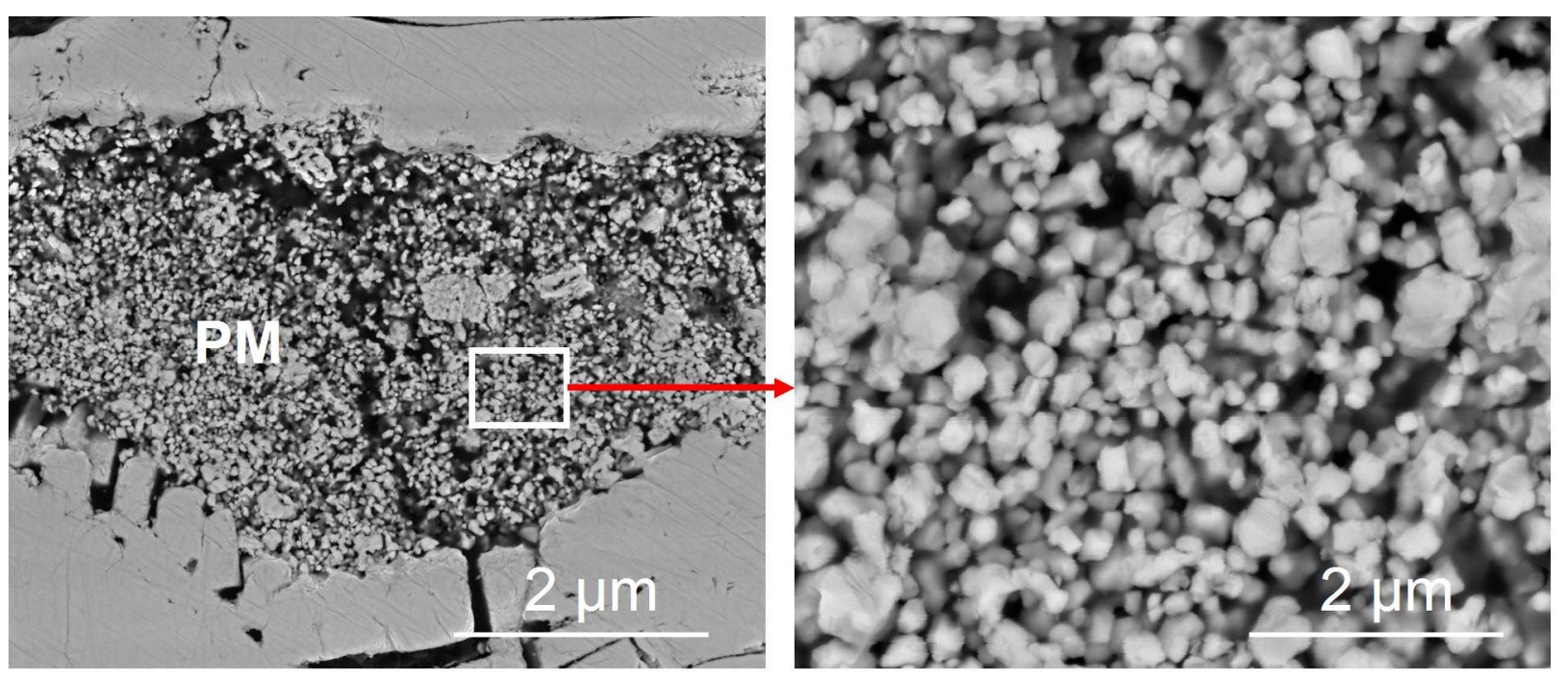

Figure 4

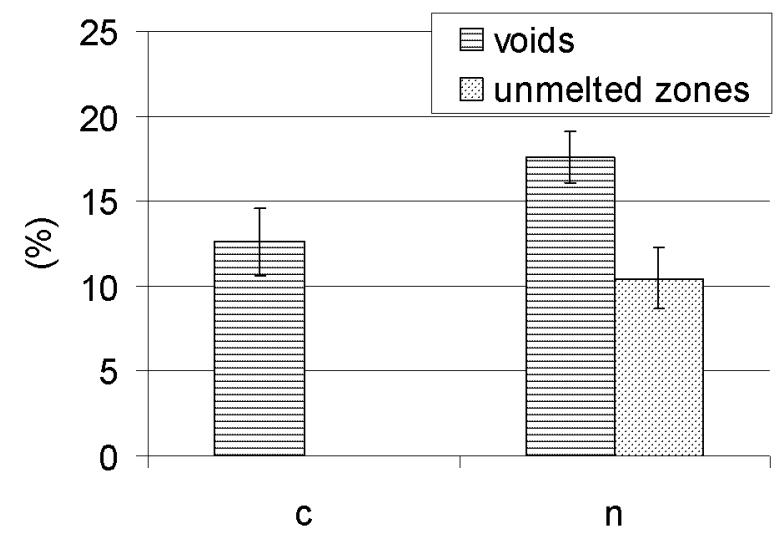

Figure 5 

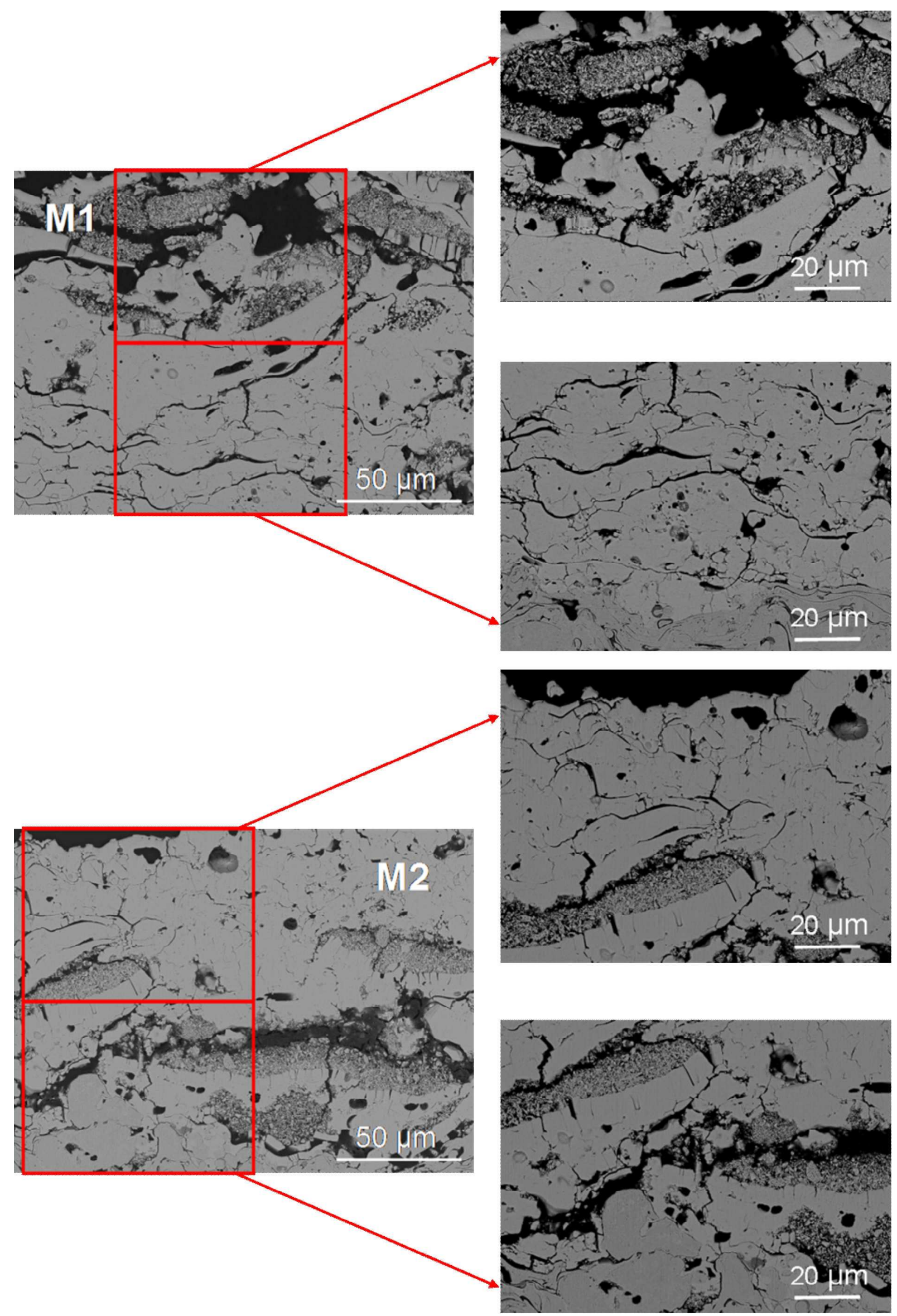

Figure 6 
G1
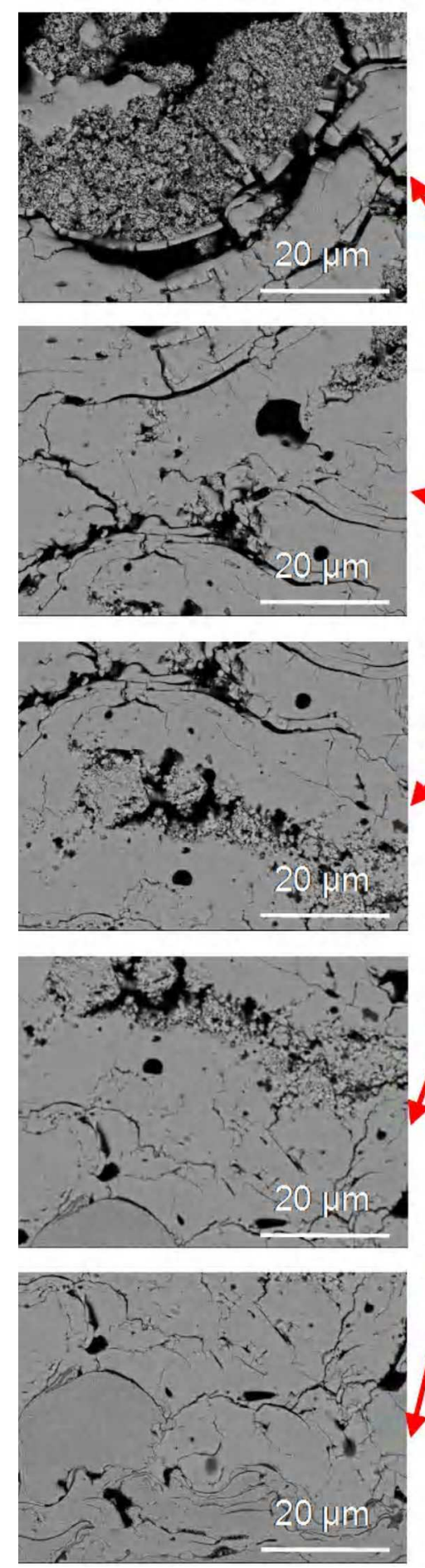

G2
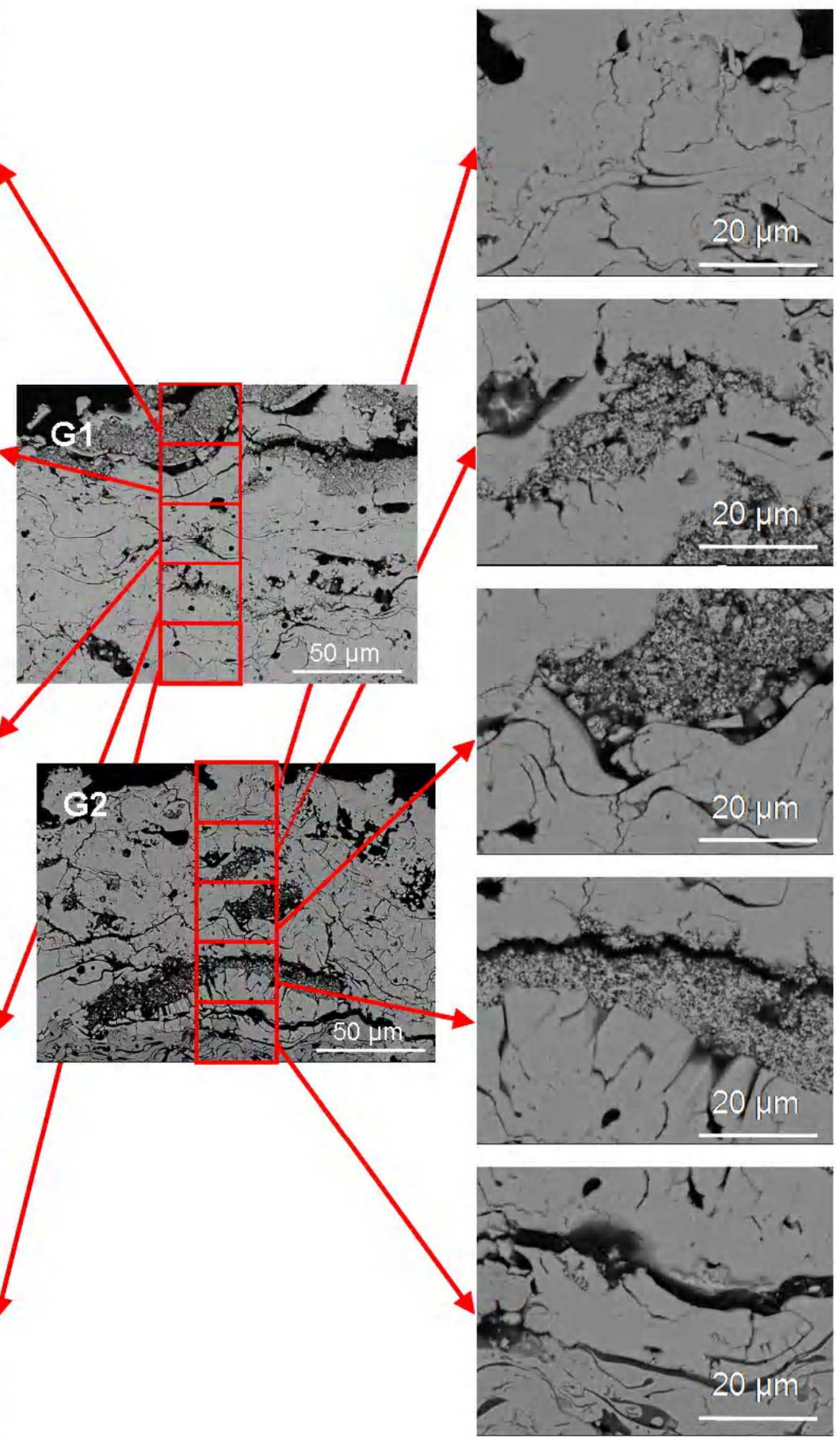

Figure 7 

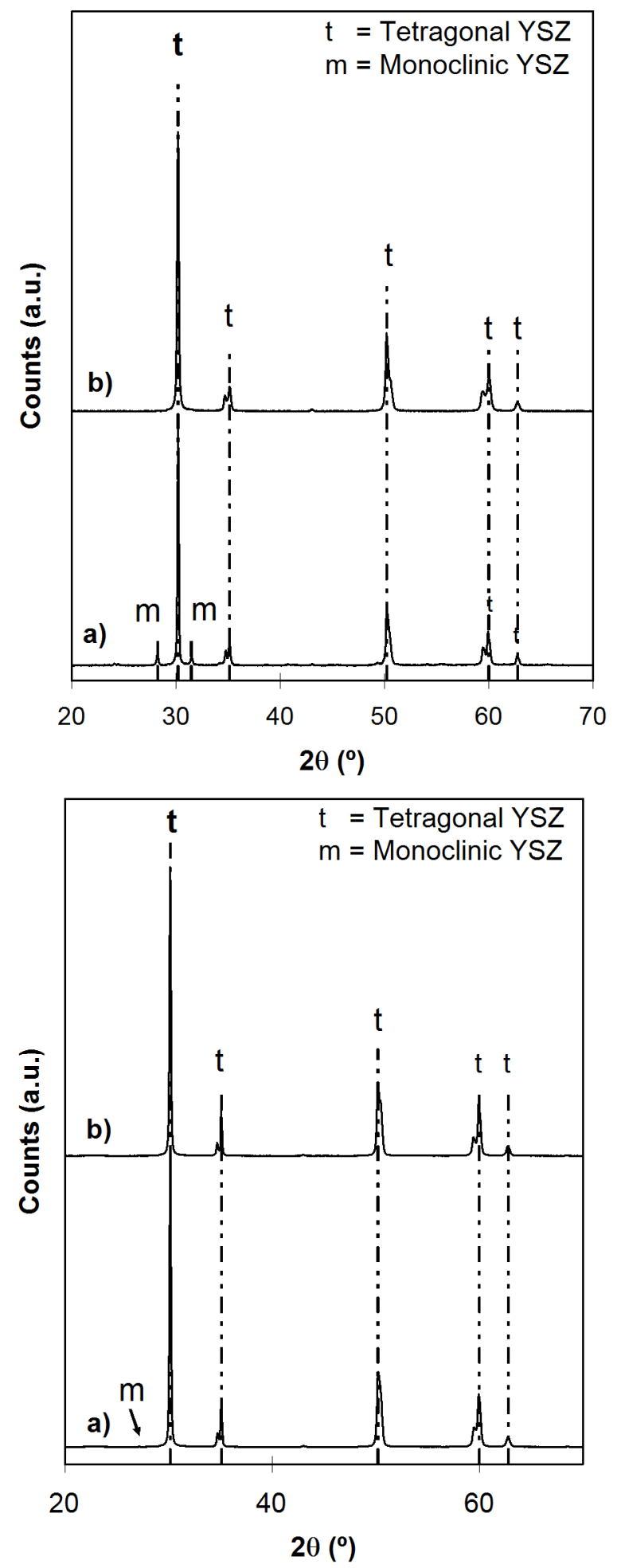

Figure 8 

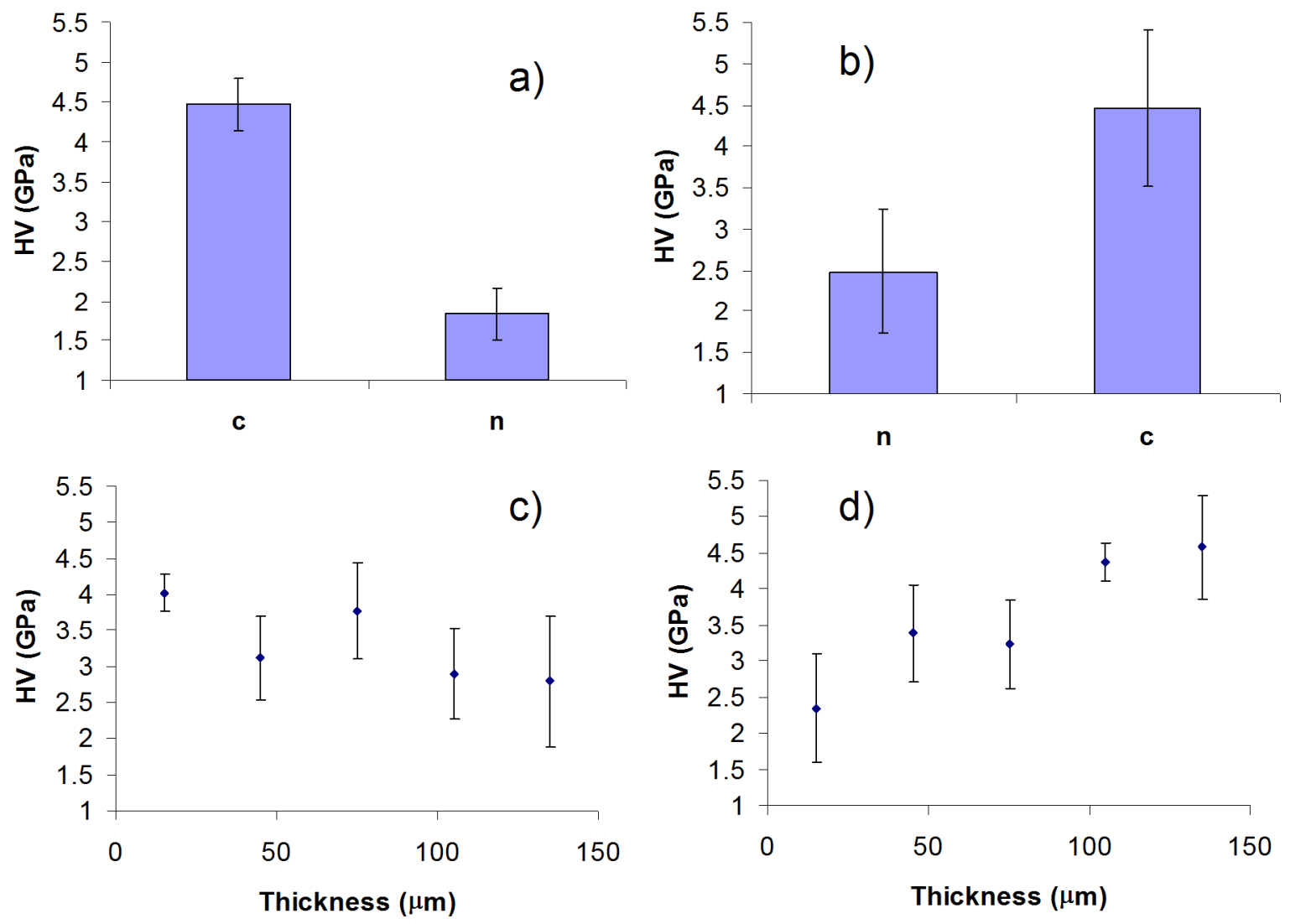

\section{Figure 9}

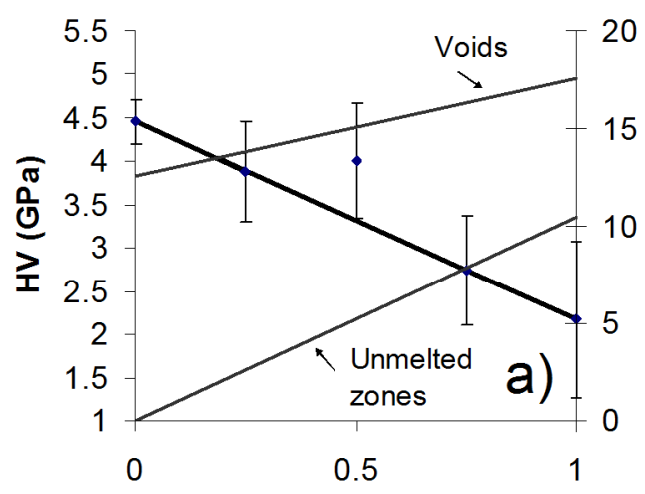

Nanostructured feedstock ratio

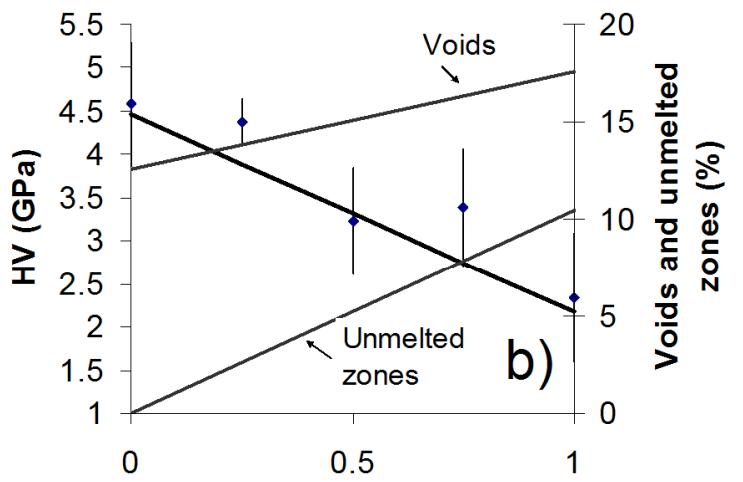

Nanostructured feedstock ratio

Figure 10 


\section{Tables}

Table 1. Characteristics of the conventional and the nanostructured commercial YSZ powder used in the study (information provided by the suppliers).

\begin{tabular}{|l|c|c|}
\cline { 2 - 3 } \multicolumn{1}{c|}{} & Conventional powder & Nanostructured powder \\
\hline Supplier & Sulzer Metco & $\begin{array}{c}\text { Inframat Advanced } \\
\text { Materials }\end{array}$ \\
\hline Reference & METCO $204 \mathrm{NS}$ & Nanox $^{\mathrm{TM}} \mathrm{S} 4007$ \\
\hline $\begin{array}{l}\mathrm{Y}_{2} \mathrm{O}_{3}: \mathrm{ZrO}_{2} \text { weight } \\
\text { ratio }\end{array}$ & $8: 92$ & $7: 93$ \\
\hline Particle size & - & $50-500 \mathrm{~nm}$ \\
\hline Agglomerate size & $11-125 \mu \mathrm{m}$ & $15-150 \mu \mathrm{m}$ \\
\hline
\end{tabular}

Table 2. Main plasma spraying parameters of each deposited feedstock in both the multilayer and the graded coating assemblies.

\begin{tabular}{|l|c|c|c|c|c|c|}
\cline { 2 - 7 } \multicolumn{1}{c|}{} & $\begin{array}{c}\mathbf{A r} \\
\left(\mathbf{s l p m}^{*}\right)\end{array}$ & $\begin{array}{c}\mathbf{H}_{2} \\
\left(\mathbf{s l p m}^{*}\right)\end{array}$ & $\begin{array}{c}\text { Intensity } \\
(\mathbf{A})\end{array}$ & $\begin{array}{c}\text { Spraying } \\
\text { distance } \\
(\mathbf{m m})\end{array}$ & $\begin{array}{c}\text { Spraying } \\
\text { speed } \\
(\mathbf{m} / \mathbf{s})\end{array}$ & $\begin{array}{c}\text { Mass flow } \\
\text { rate } \\
(\mathbf{g} / \mathbf{m i n})\end{array}$ \\
\hline Bond coat & 65 & 8 & 650 & 145 & 1 & 40 \\
\hline YSZ & 35 & 12 & 600 & 100 & 1 & 45 \\
\hline
\end{tabular}


Table 3. Make-up of the different multilayer (M) and graded (G) coating assemblies (c: conventional feedstock, $n$ : nanostructured feedstock).

\begin{tabular}{|c|c|c|c|}
\hline Reference & Description & Layers* & Passes/layer \\
\hline \multirow{2}{*}{ M1 } & \multirow{2}{*}{$\begin{array}{l}\text { Multilayer coating } \\
\qquad \mathrm{c}-\mathrm{n}\end{array}$} & $100 \% \mathrm{c}$ & 5 \\
\hline & & $100 \% \mathrm{n}$ & 5 \\
\hline \multirow{2}{*}{ M2 } & \multirow{2}{*}{$\begin{array}{l}\text { Multilayer coating } \\
\mathrm{n}-\mathrm{c}\end{array}$} & $100 \% \mathrm{n}$ & 5 \\
\hline & & $100 \% \mathrm{c}$ & 5 \\
\hline \multirow{5}{*}{ G1 } & \multirow{5}{*}{$\begin{array}{l}\text { Graded coating } \\
\quad \mathrm{c}-\mathrm{n}\end{array}$} & $100 \% \mathrm{c}$ & 2 \\
\hline & & $75 \% \mathrm{c} / 25 \% \mathrm{n}$ & 2 \\
\hline & & $50 \% \mathrm{c} / 50 \% \mathrm{n}$ & 2 \\
\hline & & $25 \% \mathrm{c} / 75 \% \mathrm{n}$ & 2 \\
\hline & & $100 \% \mathrm{n}$ & 2 \\
\hline \multirow{5}{*}{ G2 } & \multirow{5}{*}{$\begin{array}{l}\text { Graded coating } \\
\mathrm{n}-\mathrm{c}\end{array}$} & $100 \% \mathrm{n}$ & 2 \\
\hline & & $25 \% \mathrm{c} / 75 \% \mathrm{n}$ & 2 \\
\hline & & $50 \% \mathrm{c} / 50 \% \mathrm{n}$ & 2 \\
\hline & & $75 \% \mathrm{c} / 25 \% \mathrm{n}$ & 2 \\
\hline & & $0 \% \mathrm{c}$ & 2 \\
\hline
\end{tabular}

The layers were deposited in the order listed in the table 